\title{
Effects of the Covid-19 pandemic on labour markets in the western Balkans
}

\begin{abstract}
Covid-19 has had a significant effect on labour market metrics across the globe. This article aims to contribute to the understanding of the pandemic's adverse impact on labour markets in the western Balkans and the need to take appropriate measures to mitigate this effectively in the forthcoming period. Using a spread of data, we analyse and compare the distributional impacts of the pandemic recession in western Balkans labour markets in terms of the unemployment rate and the average annual growth in real minimum wages. Our analysis shows a significant deterioration of labour market trends - not least in comparison with the picture of 2019 which was broadly much more positive - which has led to increased government spending on social protection measures. This needs to be continued, not least as regards vulnerable individuals, including young people, as the pandemic continues its track. On the basis of our results, and to deal with the structural challenges presented by Balkans labour markets, there is a need for further reform and updating of regulation, social protection and policies in the labour market.
\end{abstract}

Keywords: labour market trends, Covid-19, unemployment, minimum wages, western Balkans

Introduction

The Covid-19 crisis plunged the global economy into recession in early 2020 and has profoundly affected labour markets. The world subsequently experienced a massive wave of initial job losses as a result of the pandemic and the resulting recessions. The uniqueness of pandemic recessions is the nature of the initial shock. Compared to previous recessions that were primarily caused by economic and financial shocks, the pandemic recession is characterised by having a biological nature triggered by the novel coronavirus. The adverse effect of this pandemic on labour markets had forced millions of workers across the world into temporary unemployment by the second quarter of 2020 (Gallant et al. 2020: 1).

The economic impacts of the pandemic recession have affected people's health, incomes and jobs. Beyond job losses, employment opportunities and the terms and conditions of employment have deteriorated in both developed and developing countries. Globally many workers who did not lose their jobs were faced with reduced working hours, wage cuts and forfeits of bonuses (United Nations 2011: 27). The losses from the pandemic recession thus far are enormous compared to the largest losses recorded in similar timeframes during any other modern crisis including the 
global financial crisis of 2007-2009. The pandemic recession, similar to the global financial crisis, has had a significant adverse distributional impact on job prospects. However, currently available data suggest that the dynamics of the pandemic recession is characterised by a much starker differential impact on job separation rates (Shippata 2020: 26).

A number of research studies have been conducted over a very short period of time into the economic consequences of the pandemic recession. The focus varies depending on the dimension of the economic impact which is the subject of the research. A significant part of the published studies analyses the impact on labour market trends. The key limitation of these studies is that they focus on the economic consequences of the pandemic but not on finding appropriate mechanisms to ameliorate them primarily due to an inability to predict its eventual duration (Brodeur et al. 2021: 1008).

With that in mind, the subject of this article is an analysis and comparison of the distributional impacts of the pandemic recession on labour market trends in western Balkans countries (Albania, Bosnia and Herzegovina, Kosovo, Montenegro, North Macedonia and Serbia). The intention is to perceive and determine how these countries have faced the challenges related to the increasing unemployment rate, the changing average annual growth in real minimum wages and the need to take appropriate social protection measures. The article thus focuses on two broad areas:

a. analysing and comparing the impact of the pandemic recession in terms of the significant increase in the unemployment rate

b. analysing changes in the average annual growth of real minimum wages in western Balkans countries, emphasising the importance of the appropriate measures for social protection in order to reduce the shocks of the current pandemic on labour market metrics.

The methodology we deployed in pursuit of our aims consists of qualitative research techniques such as analysis, comparative analysis and synthesis.

\section{Literature review}

Over a short period of time, a growing body of literature has examined the various labour market consequences of the Covid-19 crisis, addressing different dimensions. Numerous studies have studied the socio-economic consequences of the pandemic recession, especially the lockdowns. Social distancing and lockdown measures have been shown to have adversely affected labour markets, contributing to a drastic increase in job losses as well as changed, and deteriorated, working conditions (Brodeur et al. 2021: 1028).

Gupta et al. (2020: 18) show that the social distancing measures adopted between March and April of 2020 in response to the Covid-19 crisis have reduced the rate of new cases and deaths but increased the costs to business and workers resulting in an increase in the US unemployment rate of about 1.7 percentage points. According to Morgan Stanley's forecasts concerning the US economy, whereas the unemployment rate during the global financial crisis of 2008 rose to 10 per cent, the unemployment rate in the pandemic recession could reach up to 15 per cent, resulting in dramatic repercussions for labour markets in the forthcoming period (Li et al. 2021: section 3). 
Adams-Prassl et al. (2020: 19) find a discrepancy in job/income losses regarding type of job in the US, UK and Germany. Furthermore the findings show that workers who could not perform any of their tasks from home and workers with lower incomes have been more significantly affected by the pandemic. Younger workers and workers with lower levels of education are also more likely to experience significant cuts in their income. Similar results are shown by Alstadsæter et al. regarding the disproportionate impact of the pandemic on the population of financially vulnerable people in Norway (Alstadsæter et al. 2020: 2).

Economies and labour markets have been affected dramatically by the pandemic recession with significant impacts reflected in a sharp decline in GDP growth, the unemployment rate, consumption and living standards. The consequences of the pandemic have been applied across the entire world but the impact across countries is disproportionate, with European countries and the US experiencing the most dramatic effects thus far (ILO 2020: 7). The Covid-19 pandemic plunged the countries of the western Balkans into a deep recession as well, with tourism-dependent countries (Montenegro, Albania and Kosovo) suffering an especially critical hit (Gjermeni and Lika 2020: 8).

\section{Unemployment during the pandemic in western Balkans countries}

With the onset of the Covid-19 crisis, the economies and labour markets of the western Balkans faced a severe blow. Following the introduction of social distancing and lockdown measures, dramatic consequences and repercussions have emerged which are similar to those in other countries. The impact of the Covid-19 pandemic on economies, both globally and within the western Balkans region, primarily depends on the degree of involvement of each economy in global value chains, the level of sectoral diversification and the degree of the introduction of restrictive measures, as well as the flexibility of individual sectors in response to lockdown measures. As the epidemic has continued to spread across the region, it has become increasingly clear that the countries of the western Balkans have had to face particularly damaging economic recession.

The labour market trends of the western Balkans region during 2019, characteristic of the last two decades, were marked by low activity rates and high levels of informality as well as high unemployment rates, especially among vulnerable sectors of the working population including women and young people. However, the economic outlook for 2019 was promising with relatively high growth rates in most economies and a declining trend in rates of unemployment (RCC 2020: 4). With the outbreak of the pandemic, significant pressure emerged on western Balkans markets with the following structural challenges identified (OECD 2020: 8-9):

- the level of informality in western Balkan countries remains high in terms of the number of people employed as well as in the share of total output. A significant feature is that western Balkans countries have different profiles of formality. Consequently men are significantly more involved in informal employment in Kosovo, Montenegro and North Macedonia whereas the situation is completely the opposite in Serbia where women are significantly more represented in informal employment. Albania has barely any gender difference in terms of formal 
employment. Furthermore, workers with lower levels of education, as well as those employed in agriculture, are more likely to experience informal employment

- the average unemployment rate in western Balkans countries was around 16 per cent in 2020. More alarmingly, approximately 23 per cent of young people were not in employment, education or training in 2020 (see Figure 1)

- the biggest challenge for women in accessing economic opportunities in the western Balkans is the gender gap in labour markets.

Figure 1 - Unemployment in the six countries of the western Balkans, 2020 (\%)

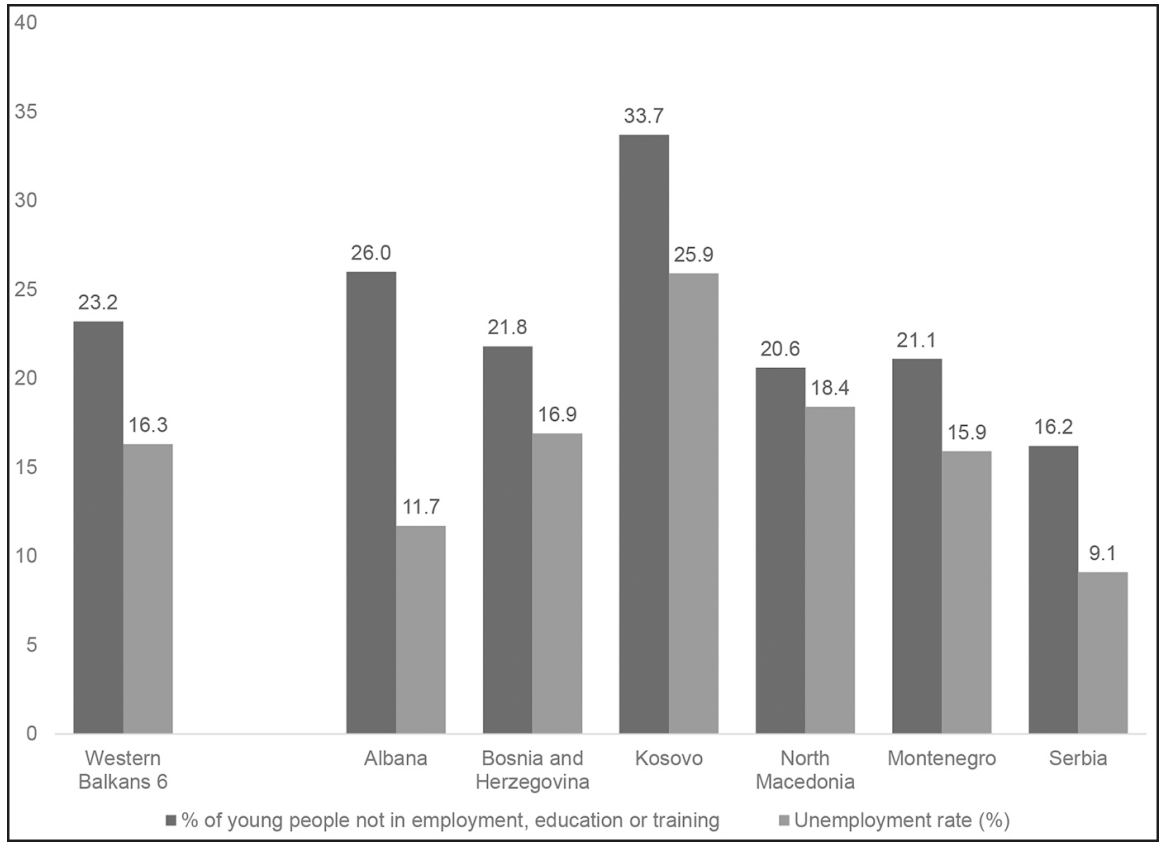

Source: World Bank World Development Indicators (https://databank.worldbank.org/source/world-dev elopment-indicators); International Labour Organization Share of youth not in employment, education or training (NEET) by sex and age (\%)

(https://www.ilo.org/shinyapps/bulkexplorer4/?lang=en\&segment=indicator\&id=EIP_NEET_SEX_A GE_RT_A)

In order to protect workers and prevent job losses, western Balkan countries have taken various measures in response to the Covid-19 pandemic. The most significant measures are as follows (OECD 2020: 8-9):

- reducing workers' exposure to Covid-19 in the workplace

- financial support for workers' incomes

- facilitated access to social protection support

- facilitated access to unemployment support. 
In addition to the adopted measures, the key criterion regarding their implementation is the relative efficiency with which this is being conducted. Clearly, this is likely to vary.

Average annual growth in real minimum wages in the western Balkans

Although more than one year has passed since the beginning of the Covid-19 crisis, there is still great uncertainty about the pace of economic recovery in countries around the world. Wage setting and wages are considered to play a crucial role in facilitating inclusive and rapid recovery. On the one hand, wage-setting mechanisms need to be flexible enough to be able to respond adequately to new conditions in order to prevent job losses. But, at the same time, it is important to maintain wage levels in order to preserve revenue and meet demand. Balancing these two imperatives is not an easy task and the social partners and governments have had to face the task of renewing collective agreements and negotiating or deciding to increase minimum wages (Molina 2021).

Figure 2 - Average annual growth in real minimum wages in the western Balkans

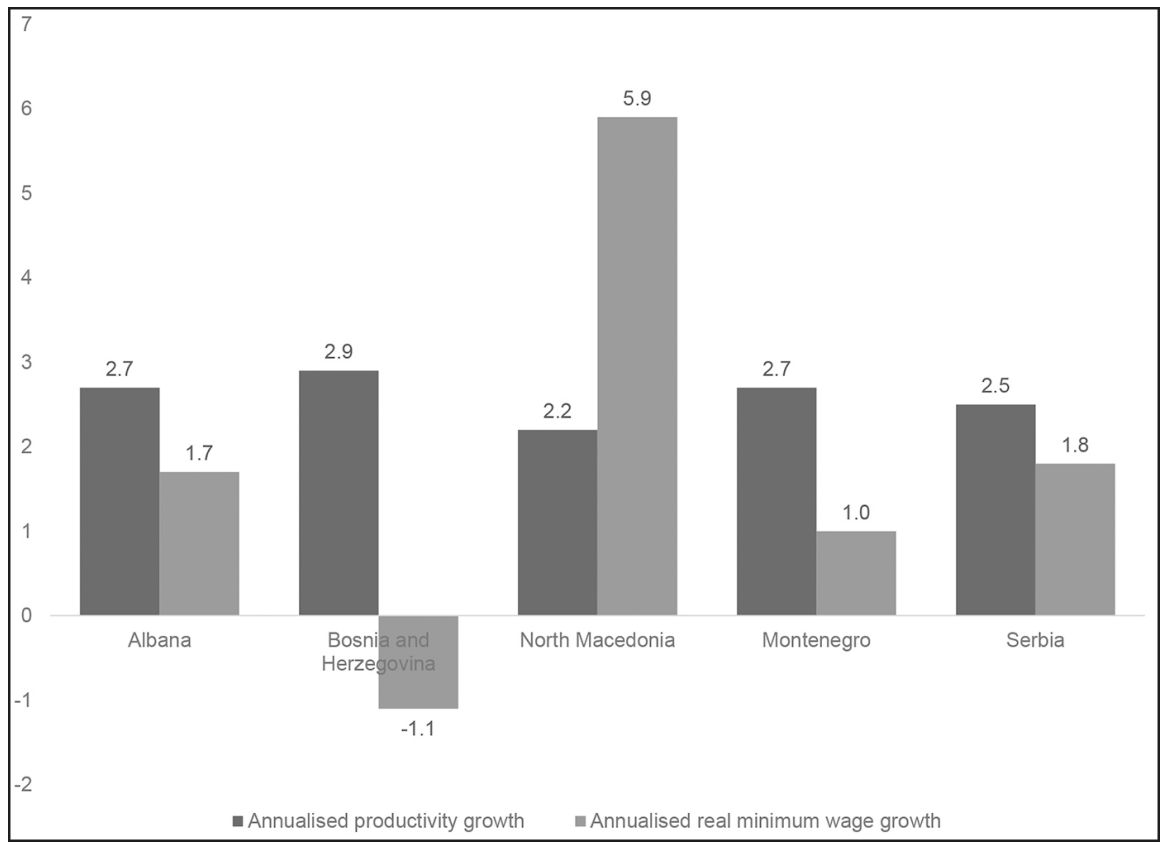

Data for Kosovo not available.

Source: ILO minimum wage database for minimum wage level; International Monetary Fund World Economic Outlook database (October 2020) for inflation (end-period consumer prices). 
Minimum wages increased in most western Balkan countries in 2020 (see Figure 2 ). The highest average annual growth in real minimum wages for 2020 was registered in North Macedonia (5.9 per cent), significantly higher than productivity growth, while there was a negative average annual growth in real minimum wages registered in Bosnia and Herzegovina (-1.1 per cent). Granting higher minimum wages for 2021 is particularly relevant in the current pandemic context. Raising minimum wages will have a stronger impact on vulnerable populations, thereby contributing to reducing some of the inequalities introduced by the Covid-19 crisis.

\section{Conclusion}

Labour markets in the western Balkans have been hit hard by the Covid-19 pandemic and have experienced significant structural consequences on top of the problems that already exist. The governments of western Balkans countries should focus policy objectives on addressing the consequences of the pandemic as well as seeking to strengthen them as a defensive measure in respect of future economic downturns.

Meanwhile, short-term government measures should continue to provide financial support to workers affected by the crisis in terms of job losses and reduced wages. These measures should particularly target vulnerable individuals such as young people, low-skilled workers and migrants as well as workers in the informal economy.

Regarding the average annual growth in the real minimum wage, this is in line with the context of the pandemic and implies a significant level of support for the vulnerable population in reducing and overcoming the inequalities introduced by the crisis.

\section{References}

Adams-Prassl, A, T. Boneva, M. Golin and C. Rauh (2020) 'Inequality in the impact of the Coronavirus shock: evidence from real time surveys' Discussion Paper Series No. 13183, IZA Institute of Labor Economics: Bonn.

Alstadsæter, A, B. Bratsberg, G. Eielsen, W. Kopczuk, S. Markussen, O. Raaum and K. Røed (2020) 'The first weeks of the Coronavirus crisis: Who got hit, when and why? Evidence from Norway' NBER Working Paper Series 27131, National Bureau of Economic Research: Cambridge, MA.

Brodeur, A, D. Gray, A. Islam and S. Bhuiyan (2021) 'A literature review of the economics of COVID-19' Journal of Economic Surveys 35 (4): 1077-1044.

Gallant, J, K. Kroft, F. Lange and M. Notowidigdo (2020) 'Temporary employment and labor market dynamics during COVID-19 recession' NBER Working Paper Series 27924, National Bureau of Economic Research: Cambridge, MA.

Gjermeni, E and A. Lika (2020) 'COVID-19 impact in the Western Balkans: Deepdive in Albania and how the pandemic impacted the SDG's Sustainable Development Goals'.

Gupta, S, L. Montenovo, T. Nguyen, F. Rojas, I. Schmutte, K. Simon, B. Weinberg and C. Wing (2020) 'Effects of social distancing policy on labor market out- 
comes' NBER Working Paper Series 27280, National Bureau of Economic Research: Cambridge, MA.

International Labour Organization (2020) 'Impact of the COVID-19 pandemic on the labor market in the occupied Palestinian territory: a forecasting model assessment' International Labour Organization: Geneva.

Li, Z, P. Farmanesh, D. Kirikkaleli and R. Itani (2021) 'A comparative analysis of COVID-19 and global financial crises: evidence from US economy' Economic Research published online 23 July 2021.

Molina, O (2021) 'Impact of the COVID-19 crisis on wages and wage setting' accessed 9 November 2021 at: https://www.eurofound.europa.eu/publications/articl e/2021/impact-of-the-covid-19-crisis-on-wages-and-wage-setting.

OECD (2020) 'The Covid-19 crisis in the Western Balkans: economic impact, policy responses, and short-term sustainable solutions' OECD: Paris, accessed 9 November 2021 at: https://www.oecd.org/south-east-europe/COVID-19-Crisis-R esponse-Western-Balkans.pdf.

Regional Cooperation Council (2020) 'Labour markets in Western Balkans: 2019 and 2020' Rcc: Sarajevo, accessed 9 November 2021 at: https://www.rcc.int/pubs /120/labour-markets-in-the-western-balkans-2019-and-2020.

Shibata, Ippei (2020) 'The distributional impact of recessions: the global financial crisis and the pandemic recession' IMF Working Paper 20/96, IMF: Washington DC, accessed 9 November 2021 at: https://www.imf.org/en/Publications/WP/Issu es/2020/06/19/The-Distributional-Impact-of-Recessions-the-Global-Financial-Cri sis-and-the-Pandemic-49492.

United Nations (2011) 'The global social crisis: report on the world social situation 2011' New York: United Nations Publications.

World Bank (a) GDP growth (annual \%) accessed 9 November 2021 at: https://data. worldbank.org/indicator/NY.GDP.MKTP.KD.ZG?view=chart.

World Bank (b) Unemployment rates (\%) accessed 9 November at: https://data.world bank.org/indicator/SL.UEM.TOTL.ZS?view=chart.

Dr. Azemina Mashovic is Reader in the Integrated Business Faculty, Str. '3-ta Makedonska Brigada' 66A - Floor 1, 1000 SKOPJE, North Macedonia. e-mail: azemina@fbe.edu.mk.

Dr. Tatjana Dragičević Radičević is Associate Professor at University Business Academy in Novi Sad, Faculty of Applied Management, Economics and Finance, Jevrejska 24, 11158 BEOGRAD, Serbia. e-mail: tatjana.dragicevic@mef.edu.rs.

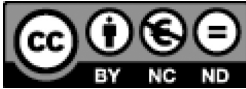

(C) Azemina Mashovic and Tatjana Dragičević Radičević 
